\title{
Unanticipated Money, Output, and the Price Level in the United States
}

\section{Citation}

Barro, Robert J. 1978. Unanticipated money, output, and the price level in the United States. Journal of Political Economy 86(4): 549-580.

\section{Published Version}

doi:10.1086/260699

\section{Permanent link}

http://nrs.harvard.edu/urn-3:HUL.InstRepos:3450988

\section{Terms of Use}

This article was downloaded from Harvard University's DASH repository, and is made available under the terms and conditions applicable to Other Posted Material, as set forth at http:// nrs.harvard.edu/urn-3:HUL.InstRepos:dash.current.terms-of-use\#LAA

\section{Share Your Story}

The Harvard community has made this article openly available.

Please share how this access benefits you. Submit a story.

Accessibility 


\title{
Unanticipated Money, Output, and the Price Level in the United States
}

\section{Robert J. Barro}

\author{
University of Rochester
}

\begin{abstract}
Earlier analysis of unanticipated money growth is extended to output (GNP) and the price level (GNP deflator) for recent U.S. experience. Price level determination is more complicated than output determination, because both anticipated and unanticipated money movements are involved. Empirical results accord well with the model-notably, they support the key hypothesis of a one-to-one, contemporaneous link between anticipated money and the price level. Precise estimates are obtained for the lagged responses of output and prices to unanticipated money movements. Cross-equation comparisons indicate that the price response to unanticipated money movements has a longer lag than the output response. A form of lagged adjustment in money demand can account for this difference. The forecasts for inflation average 5.5 percent per year for 1977-80.
\end{abstract}

In an earlier empirical study (Barro 1977a), I discussed the concept of unanticipated money growth and the hypothesis that only this component of monetary change would influence real variables like the unemployment rate. The present study applies the analysis to output and extends the framework to a consideration of the price level and hence to the rate of inflation. The nature of the monetary influence on the price level is more complicated than that for output or the unemployment rate, because both anticipated and unanticipated movements in money must be taken into

This work is part of a project on money, expectations, and economic activity that is being supported by the National Science Foundation. The present research was completed while I was a national fellow at the Hoover Institution. Portions of this paper will be included in a study of inflation by the U.S. Treasury. I have benefited from comments by Takeshi Amemiya, Paul Evans, Herschel Grossman, Bob Hall, Bronwyn Hall, Leonardo Leiderman, Bob Lucas, Ben McCallum, Franco Modigliani, and Hal White.

[ Journal of Political Economy, 1978, vol. 86. no. 4]

(C) 1978 by The University of Chicago. 0022-3808/78/8604-0001 $\$ 02.49$ 
account. In fact a key hypothesis to be tested is that anticipated movements in the money stock (with expected rate of inflation-type effects held fixed) would be reflected in one-to-one, contemporaneous movements of the price level.

This paper reports empirical results on the relation of money to output (real GNP) and the price level (the GNP deflator) for the post-World War II period in the United States. The results for output are basically satisfactory and resemble the earlier findings for unemployment. The results for the price level also accord well with the underlying model-in particular, the hypothesis of a one-to-one, contemporaneous link between anticipated money and the price level is supported by the empirical evidence. The results also provide precise estimates of the lagged response of the price level and the rate of inflation to unanticipated money movements. Substantial space is devoted to a cross-equation comparison of the output and price level responses to monetary movements. The price level response appears to be drawn out relative to the output response. However, the two patterns can be reconciled by a form of lagged adjustment in the moneydemand function.

The first part of the paper deals with the money-growth process, the second part with output, and the third part with the price level. Part IV discusses predictions for 1977 onward, while Part V combines the various pieces of the analysis to simulate a dynamic "Phillips curve." The last part discusses some promising extensions of the research.

\section{Money-Growth Equation}

The money-growth equation, which is used to divide observed money growth into anticipated and unanticipated components, corresponds in form to the expression that was used in my earlier analysis (Barro 1977a, pp. 101-5). In this formulation the money-growth rate is related to a measure of federal government expenditure relative to normal (which captures an aspect of the revenue motive for money creation), a lagged measure of the unemployment rate (which reflects countercyclical response of money growth), and two annual lagged values of money growth (which pick up persistence effects not captured by the other explanatory variables). Aside from an extension of the sample to 1976, the only change from the previous setup is that the estimation now weighs the World War II observations less heavily than the postwar values. This differential weighting is appropriate because of the larger error variance that apparently prevailed during the war. Each variable observation from 1941 to 1945 is multiplied by 0.36 - a value that was determined iteratively along with the estimation of the money-growth equation from a maximum likelihood criterion. Each observation from 1946 to 1976 receives a unit weight in the estimation. 
Using annual observations from 1941 to 1976, the estimated moneygrowth equation is, with standard errors in parentheses,

$D M_{t}=$

$$
\begin{array}{lll}
0.082+0.41 D M_{t-1}+0.21 D M_{t-2} & +0.072 F E D V_{t}+ & 0.026 U N_{t-1} \\
(0.027)(0.14) & (0.12) & (0.016)
\end{array}
$$

$$
R^{2} \text { (weighted) }=0.77, \mathrm{D}-\mathrm{W}=1.9, \hat{\sigma}=0.015,
$$

where D-W is the Durbin-Watson statistic, ${ }^{1} \hat{\sigma}$ is the standard error of estimate (applying to the error term for the post-World War II period), $M$ is an annual average of the $M 1$ definition of the money stock, and $D M_{t} \equiv \log \left(M_{t}\right)-\log \left(M_{t-1}\right)$ is the annual average growth rate of money. The variable $F E D V_{t} \equiv \log \left(F E D_{t}\right)-[\log (F E D)]_{t}^{*}$ measures federal expenditure relative to "normal," where $F E D_{t}$ is current real expenditure and $[\log (F E D)]_{t}^{*}$ is an exponentially declining distributed lag of current and past values of $\log (F E D)$, using an adaptation coefficient of 0.2 per year (as discussed in Barro 1977a, p. 103). The variable $U N \equiv \log (U / 1-U)$ is a cyclical variable, where $U$ is the unemployment rate in the total labor force.

The main difference between the present estimates and the earlier ones appears in the estimated coefficients of the lagged money-growth variables, $D M_{t-1}$ and $D M_{t-2}$, which are now $0.41,0.21$, as compared with the previous estimates, $0.24,0.35$. The suggestion of negative serial correlation of the residuals in the earlier equation, for which the estimate of the firstorder serial correlation coefficient was -.35 , is absent in the present results (see n. 1). These differences stem from the lower weight that is now attached to the World War II observations.

The estimated values from equation (1), $\widehat{D M}_{t}$, and the residuals, $D M R_{t} \equiv D M_{t}-\widehat{D M}_{t}$, are used to measure, respectively, the anticipated and unanticipated components of money growth. This concept of anticipated money growth is discussed in the earlier study (pp. 105-6). The estimated values, $\widehat{D M}$ and $D M R$, are indicated along with values of actual money growth in table 1 , columns $1-3$.

\section{Output Equation}

The form of the equation for output (real GNP) is similar to that specified for the unemployment rate in my earlier work. The hypothesis that money growth influences output only when this growth is unanticipated implies that current and lagged values of DMR enter the output equation, but current and lagged values of actual money growth, $D M$, are excluded.

\footnotetext{
1 The value of the Durbin $h$-statistic, which is more appropriate in a model with a lagged dependent variable (see, e.g., Maddala 1977, p. 372), is 0.6, which differs insignificantly from zero.
} 
TABLE 1

Values of Money Growth and Output

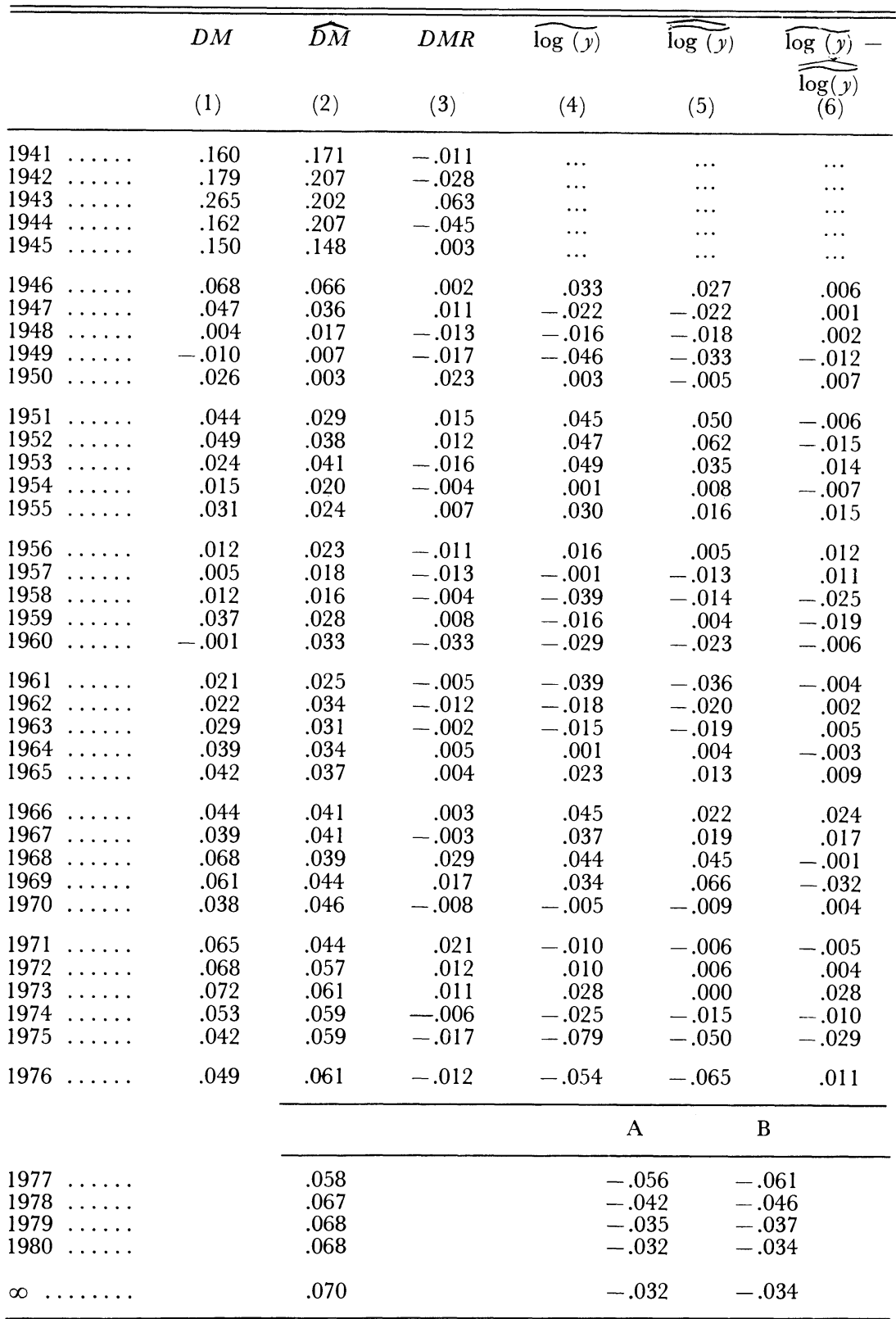

Note. $-D M_{t} \equiv \log \left(M_{t}\right)-\log \left(M_{t-1}\right)$, where $M$ is an annual average of $M_{1}$ from recent issues of the Federal Reserve Bulletin, incorporating the revision of data from the February 1976 issues. $\widehat{D M}$ is the estimated value from eq. (1). Predicted values for 1977 and later years use the 1976 value of $F E D V(0.18) . D M R \equiv D M$ $-\widehat{D M}$. $y$ is real GNP in 1972 dollars (U.S. Council of Economic Advisers 1977, p. 188). For 1946-76, $\log \left(y_{t}\right) \equiv \log \left(y_{t}\right)-2.985-0.0354 \cdot t$ is output relative to trend based on the estimated constant $(2.953+$ $0.549(\overline{M I L})$, where $\overline{M I L}=0.0585$ is the mean value of the military variable over the $1946-76$ period) and time trend in eq. (3). $\overline{\log (y)}$ from 1946 to 76 is the estimated value based on eq. (3). From 1977 on, predicted values labeled $A$ are based on the estimated output eq. (3). Values labeled $B$ are based on the jointly estimated coefficients shown in eq. (13). Output predictions assume that $M I L=D M R=0$ from 1977 on. 
Empirically, the contemporaneous and three annual lag values of $D M R$ turn out to be important for explaining output. The persisting output effect of monetary shocks implied by the inclusion of lagged values of the $D M R$ variable can be rationalized from the impact of shocks on stock variables, such as stocks of productive capital (Lucas 1975), which are carried forward into future periods. An analogous argument, based on adjustment costs for changes in labor input, is developed in Sargent (1977).

In addition to monetary influences, the output equation includes a time-trend variable-intended to capture the secular movement of "normal" output-and the military-personnel (draft-pressure) variable, MIL (tabulated in table 2), that was included in my previous study of unemployment. ${ }^{2}$ In that study (pp. 106-7) the military variable was viewed as measuring the incentive, operating through differential probabilities of being conscripted into the military, for avoiding the status "unemployed." For example, the incentive to stay in school or to take a job rather than be unemployed was viewed as a response to the military draft-partly reflected in reduced labor-force participation rates and partly in higher employment rates of labor-market participants-that would show up as a corresponding reduction in unemployment rates. Subsequent analysis that $\mathrm{I}$ have carried out on unemployment rates stratified by sex and age (to be reported) indicates that the response to the military variable is concentrated in younger males, which supports the interpretation of this variable as a draft-pressure effect on labor supply rather than an aggregate demand effect. With respect to output, the military variable would be expected to operate positively only through the induced employment response, since the effects that involve a disincentive to labor-force participation would operate inversely on output. ${ }^{3}$ Hence the argument for including the military variable as an expansionary element is less persuasive in the case of output than in the case of the unemployment rate.

The form of the output equation is

$$
\begin{aligned}
\log \left(y_{t}\right)=a_{0}+a_{1} D M R_{t}+a_{2} D M R_{t-1} & +a_{3} D M R_{t-2}+a_{4} D M R_{t-3} \\
& +a_{5} M I L_{t}+a_{6} t+u_{t}, \quad(2)
\end{aligned}
$$

where $y$ is real GNP in 1972 dollars and $u_{t}$ is a stochastic term with the usual properties.

${ }^{2}$ A contemporaneous or lagged value of a terms-of-trade variable is insignificant when added to the output equation. The $M I L$ variable is defined as the ratio of military personnel to the male population aged 15-44 for years in which a selective draft was in operation. The variable takes on a zero value at other times (parts of 1947-48 and 197076). See $n$. 4 below on the effect of removing the distinction between years that do and do not have a selective draft. A minimum-wage-rate variable, which appeared in my previous analysis of unemployment, is insignificant when added to the output equation.

${ }^{3}$ To the extent that draftees receive lower wages than they would in alternative civilian occupations, there would be an additional negative effect of the military variable on measured GNP. 
TABLE 2

Values of the Price Level, Inflation Rate, and Other Variables

\begin{tabular}{|c|c|c|c|c|c|c|c|c|}
\hline & $\log _{(1)}(P)$ & $\widehat{\log _{(2)}(P)}$ & $\frac{\operatorname{og}(P)-}{\log _{(3)}(P)}$ & $\begin{array}{l}D P \\
(4)\end{array}$ & $\begin{array}{l}\widehat{D P} \\
(5)\end{array}$ & $\begin{array}{c}r \\
(6)\end{array}$ & $\begin{array}{l}G / y \\
(7)\end{array}$ & $\begin{array}{c}M I L \\
(8)\end{array}$ \\
\hline $1945 \ldots$ & -.968 & -.545 & -.422 & .024 & $\ldots$ & .026 & .416 & .350 \\
\hline $\begin{array}{l}1946 \ldots \\
1947 \ldots \\
1948 \ldots \\
1949 \ldots \\
1950 \ldots\end{array}$ & $\begin{array}{r}-.823 \\
-.699 \\
-.633 \\
-.642 \\
-.624\end{array}$ & $\begin{array}{l}-.636 \\
-.626 \\
-.632 \\
-.626 \\
-.627\end{array}$ & $\begin{array}{r}-.189 \\
-.073 \\
-.001 \\
-.016 \\
.003\end{array}$ & $\begin{array}{r}.145 \\
.125 \\
.066 \\
-.010 \\
.019\end{array}$ & $\begin{array}{l}\ldots \\
\ldots \\
.068 \\
.007 \\
.016\end{array}$ & $\begin{array}{l}.025 \\
.026 \\
.028 \\
.027 \\
.026\end{array}$ & $\begin{array}{l}.122 \\
.077 \\
.087 \\
.100 \\
.088\end{array}$ & $\begin{array}{l}.105 \\
.012(.048) \\
.022(.044) \\
.048 \\
.049\end{array}$ \\
\hline $\begin{array}{l}1951 \ldots \\
1952 \ldots \\
1953 \ldots \\
1954 \ldots \\
1955 \ldots\end{array}$ & $\begin{array}{r}-.557 \\
-.545 \\
-.529 \\
-.516 \\
-.494\end{array}$ & $\begin{array}{l}-.573 \\
-.546 \\
-.523 \\
-.524 \\
-.491\end{array}$ & $\begin{array}{r}.016 \\
.001 \\
-.006 \\
.009 \\
-.004\end{array}$ & $\begin{array}{l}.066 \\
.012 \\
.015 \\
.013 \\
.022\end{array}$ & $\begin{array}{l}.050 \\
.011 \\
.022 \\
.005 \\
.025\end{array}$ & $\begin{array}{l}.029 \\
.030 \\
.032 \\
.029 \\
.031\end{array}$ & $\begin{array}{l}.141 \\
.179 \\
.184 \\
.155 \\
.133\end{array}$ & $\begin{array}{l}.092 \\
.106 \\
.105 \\
.099 \\
.090\end{array}$ \\
\hline $\begin{array}{l}1956 \ldots \\
1957 \ldots \\
1958 \ldots \\
1959 \ldots \\
1960 \ldots\end{array}$ & $\begin{array}{r}-.464 \\
-.431 \\
-.414 \\
-.393 \\
-.375\end{array}$ & $\begin{array}{r}-.463 \\
-.434 \\
-.419 \\
-.383 \\
-.387\end{array}$ & $\begin{array}{r}.000 \\
.003 \\
.005 \\
-.010 \\
.012\end{array}$ & $\begin{array}{l}.031 \\
.033 \\
.017 \\
.021 \\
.017\end{array}$ & $\begin{array}{l}.031 \\
.030 \\
.012 \\
.031 \\
.006\end{array}$ & $\begin{array}{l}.034 \\
.039 \\
.038 \\
.044 \\
.044\end{array}$ & $\begin{array}{l}.128 \\
.132 \\
.137 \\
.127 \\
.123\end{array}$ & $\begin{array}{l}.083 \\
.081 \\
.075 \\
.073 \\
.071\end{array}$ \\
\hline $\begin{array}{l}1961 \ldots \\
1962 \ldots \\
1963 \ldots \\
1964 \ldots \\
1965 \ldots\end{array}$ & $\begin{array}{r}-.367 \\
-.348 \\
-.334 \\
-.319 \\
-.297\end{array}$ & $\begin{array}{r}-.364 \\
-.337 \\
-.328 \\
-.318 \\
-.312\end{array}$ & $\begin{array}{r}-.003 \\
-.011 \\
-.006 \\
.000 \\
.015\end{array}$ & $\begin{array}{l}.009 \\
.018 \\
.014 \\
.015 \\
.022\end{array}$ & $\begin{array}{l}.012 \\
.030 \\
.020 \\
.016 \\
.007\end{array}$ & $\begin{array}{l}.044 \\
.043 \\
.043 \\
.044 \\
.045\end{array}$ & $\begin{array}{l}.127 \\
.129 \\
.123 \\
.115 \\
.109\end{array}$ & $\begin{array}{l}.071 \\
.077 \\
.073 \\
.072 \\
.071\end{array}$ \\
\hline $\begin{array}{l}1966 \ldots \\
1967 \ldots \\
1968 \ldots \\
1969 \ldots \\
1970 \ldots\end{array}$ & $\begin{array}{r}-.264 \\
-.236 \\
-.191 \\
-.143 \\
-.090\end{array}$ & $\begin{array}{r}-.279 \\
-.238 \\
-.176 \\
-.127 \\
-.077\end{array}$ & $\begin{array}{r}.015 \\
.002 \\
-.015 \\
-.016 \\
-.012\end{array}$ & $\begin{array}{l}.033 \\
.028 \\
.044 \\
.049 \\
.053\end{array}$ & $\begin{array}{l}.018 \\
.026 \\
.059 \\
.064 \\
.065\end{array}$ & $\begin{array}{l}.051 \\
.055 \\
.062 \\
.070 \\
.080\end{array}$ & $\begin{array}{l}.115 \\
.124 \\
.122 \\
.113 \\
.103\end{array}$ & $\begin{array}{c}.079 \\
.086 \\
.087 \\
.085 \\
0(.075)\end{array}$ \\
\hline $\begin{array}{l}1971 \ldots \\
1972 \ldots \\
1973 \ldots \\
1974 \ldots \\
1975 \ldots\end{array}$ & $\begin{array}{r}-.041 \\
.000 \\
.056 \\
.152 \\
.241\end{array}$ & $\begin{array}{r}-.054 \\
-.003 \\
.057 \\
.154 \\
.231\end{array}$ & $\begin{array}{r}.013 \\
.003 \\
.000 \\
-.003 \\
.009\end{array}$ & $\begin{array}{l}.050 \\
.041 \\
.056 \\
.095 \\
.089\end{array}$ & $\begin{array}{l}.036 \\
.038 \\
.057 \\
.098 \\
.079\end{array}$ & $\begin{array}{l}.074 \\
.072 \\
.074 \\
.086 \\
.088\end{array}$ & $\begin{array}{l}.094 \\
.087 \\
.078 \\
.079 \\
.080\end{array}$ & $\begin{array}{l}0(.065) \\
0(.056) \\
0(.052) \\
0(.048) \\
0(.046)\end{array}$ \\
\hline \multirow[t]{2}{*}{$1976 \ldots$} & .291 & .293 & -.002 & .050 & .052 & .084 & .076 & $0(.045)$ \\
\hline & \multicolumn{2}{|c|}{ A } & B & \multicolumn{2}{|c|}{ A } & $\mathrm{B}$ & & \\
\hline $\begin{array}{l}1977 \ldots \\
1978 \ldots \\
1979 \ldots \\
1980 \ldots\end{array}$ & \multicolumn{2}{|c|}{$\begin{array}{l}.364 \\
.420 \\
.463 \\
.504\end{array}$} & & & & $\begin{array}{l}63 \\
56 \\
50 \\
47\end{array}$ & & \\
\hline $\begin{array}{l}1981 \ldots \\
1982 \ldots\end{array}$ & \multicolumn{2}{|c|}{$\begin{array}{l}.552 \\
.607\end{array}$} & .557 & \multicolumn{2}{|c|}{.048} & .050 & & \\
\hline$\infty \ldots$. & \multicolumn{2}{|c|}{$\ldots$} & & \multicolumn{2}{|c|}{.059} & 061 & & \\
\hline
\end{tabular}

Note.- $P$ is the GNP deflator $(1972=1.0)$ (U.S. Council of Economic Advisers 1977, p. 190). Log $(P$ ) from $1945-76$ is the estimated value from eq. (9). Predicted values from 1977 on use the predicted values of $M$ implied by the money-growth-rate predictions in table 1 . The predictions also use the 1976 values of $G / y$ and $r$. Values of $D M R$ from 1977 on are assumed to be zero. Projection A uses the coefficients from eq. (9), while projection $B$ utilizes the coefficients from the joint estimation shown in eq. (13) (with lagged values up to $D M R_{t-5}$ included). $D P_{t} \equiv \log \left(P_{t}\right)-\log \left(P_{t-1}\right) . \overline{D P_{t}} \equiv \overline{\log \left(P_{t}\right)}-\log \left(P_{t-1}\right)$ (based on the actual previous value, $\log \left[P_{t-1}\right]$, up to 1977), $r$ is Moody's Aaa index of corporate bond rates (U.S. Council of Economic Advisers 1977, p. 260). $G$ is real federal government purchases of goods and services in 1972 dollars (ibid., p. 187), $y$ is defined in the note to table $1 . M I L$ is the ratio of military personnel (U.S. Council of Economic Advisers 1977, p. 218) to the male population aged 15-44 (estimated from data in U.S. Department of Commerce [1975, pp. 10, 15] and from Statistical Abstract of the U.S., various issues) for years in which a selective draft was in effect. Figures shown in parentheses are the actual values of the military personnel ratio, ignoring the absence of a selective draft for all or part of those years. 
The estimated output equation, based on annual observations from 1946 to 1976 and using the residuals from equation (1) to measure $D M R$, is $\log \left(y_{t}\right)=2.95+1.04 D M R_{t}+1.21 D M R_{t-1}+0.44 D M R_{t-2}$ $\begin{array}{llll}(0.04) \quad(0.21) \quad(0.22) & (0.21)\end{array}$

$$
\begin{array}{ccc}
0.26 D M R_{t-3} & +0.55 M I L_{t} \\
(0.16) & 0.0354 & 0.09) \\
(0.0004)
\end{array}
$$

$R^{2}=.9980, R^{2}$ with $y$ measured relative to trend $=.82, \mathrm{D}-\mathrm{W}=1.8$, $\hat{\sigma}=0.016$,

where $\hat{\sigma}$ again denotes the standard error of estimate. Additional lagged values of the $D M R$ variable are insignificant when added to equation (3). The results indicate absence of serial correlation in the residuals. Further, if a lagged value of the dependent variable, $\log \left(y_{t-1}\right)$, is added to the equation, its estimated coefficient, 0.06, standard error $=0.09$, differs insignificantly from zero.

As in the earlier case for unemployment, the output equation indicates a strong expansionary effect of current and lagged values of unanticipated money growth. The main difference from the unemployment results (Barro 1977a, p. 108 - an updated version of the unemployment-rate equation is similar in this respect) is that the pattern of lagged output response to $D M R$ shows a relatively greater weight on the contemporaneous value. (Also, the $D M R_{t-3}$ variable, which was insignificant in the case of the unemployment rate, seems to have a weak positive effect on output.) As before, the most important expansionary effect of unanticipated money growth appears in the l-year lag value, $D M R_{t-1}$.

The sum of the four $D M R$ coefficients for output, 3.0, implies that a money shock of $D M R=1$ percent per year that persisted over a 4-year period (which would be a very unusual pattern of persistence, because the anticipated value, $\widehat{D M}_{t}$, makes use of lagged observations on actual money growth) would raise output by about 3.0 percent. Since the corresponding estimated effect on the unemployment rate (starting from a value for $U$ of 5 percent) was a reduction by somewhat more than 1 percentage point, there is an implicit Okun's Law type of relation in which money-induced percentage increases in output and reductions in percentage points of the unemployment rate occur on about a three-to-one basis.

The estimated output effect of the military variable is surprisingly strong and significant, considering the discussion above of the role of this variable. In fact the estimated coefficient in equation (3) implies that militaryinduced percentage increases in output and reductions in percentage points of the unemployment rate occur on an almost three-to-one basisthat is, along about the same estimated Okun's Law relation that applies to unanticipated money movements. It is possible that the militarypersonnel variable is proxying for effects other than the influence of draft pressure on labor supply. However, the variable does not seem to be merely a proxy for government expenditure, since real government pur- 
chases of goods and services (total government or federal alone) or of defense items are insignificant when added to equation (3), with the $M I L$ variable remaining significant. ${ }^{4}$

Equation (3) also indicates an estimated trend rate of growth of real GNP of about 3.5 percent per year.

Table 1 contains actual and estimated values of output relative to trend, $\widehat{\log (y)}$, as calculated by subtracting from $\log (y)$ the estimated time trend and constant from equation (3) - see the note to table 1 for details. The estimated values of $\overline{\log (y)}$ trace out the major patterns of boom and recession that are shown by the actual values. (See Barro [1977a, pp. 11213] for a discussion of the business-cycle pattern in terms of the unemployment rate in relation to the movements in the $D M R$ series.) The equation underestimates the contraction of 1958-59, the boom in 1966-67, and the sharp cutback of output in 1975. However, the model accounts well for the immediate post-World War II behavior of output, 1946-49; for the Korean and post-Korean experience, 1951-54; and for the recession and recovery period after 1960, 1961-65. A discussion of predictions from the output equation will be deferred until Part IV below.

Following the form of my previous analysis of unemployment, I have tested the hypothesis that only the unanticipated part of monetary change, $D M R$, influences output. An estimated-output equation that substitutes current and lagged values of actual money growth, $D M$, for the $D M R$ values is

$$
\begin{aligned}
& \log \left(y_{t}\right)=3.13+0.95 D M_{t}+0.53 D M_{t-1}-0.20 D M_{t-2} \\
& \begin{array}{llll}
(0.08) \quad(0.26) \quad(0.26) \quad(0.23)
\end{array} \\
& -0.27 D M_{t-3}+0.31 M I L_{t}+0.0335 \cdot t \text {, } \\
& \text { (0.16) (0.15) (0.0007) }
\end{aligned}
$$

$R^{2}=.997, R^{2}$ with $y$ measured relative to trend $=.70, \mathrm{D}-\mathrm{W}=1.1$, $\hat{\sigma}=0.021$.

4 The estimated coefficient of the $M I L$ variable also does not depend on the inclusion of the 1970-76, nonselective draft years, for which the $M I L$ variable was set to zero (n. 2 above). If the sample is limited to the 1946-69 period, the coefficient estimates are very close to those reported in eq. (3), and a test for including the 1970-76 observations with the earlier ones yields the statistic $F_{17}^{7}=1.2$, which is well below the 5 percent critical value of 2.6. If the military variable is not set to zero for the nonselective draft years, the estimated output equation over the 1946-76 period becomes

$$
\begin{aligned}
& \log \left(y_{t}\right)=2.95+0.96 D M R_{t}+0.94 D M R_{t-1}+0.16 D M R_{t-2}+0.04 D M R_{t-3} \\
& \begin{array}{lllll}
(0.05) & (0.23) & (0.24) & (0.22) & (0.17)
\end{array} \\
& +0.97 M I L_{t}+0.0351 \cdot t \text {, } \\
& \text { (0.18) (0.0004) } \\
& R^{2}=.9977, \mathrm{D}-\mathrm{W}=1.5, \hat{\sigma}-0.017 \text {. }
\end{aligned}
$$

The standard error of estimate rises only slightly with this change in specification-from 0.016 to 0.017 -but the estimated coefficients on the $D M R_{t-2}$ and $D M R_{t-3}$ variables become insignificant, and the point estimate of the $M I L$ coefficient increases substantially. 
The relative statistical performance of equations (4) and (3) is indicated by the standard errors of estimate $(0.021$ vs. 0.016$)$ and by the D-W statistics (1.1 vs. 1.8). It is also worth noting that the estimated coefficients on $D M_{t-2}$ and $D M_{t-3}$ in equation (4) are negative (see below), although individually insignificantly different from zero.

In order to test for the irrelevance of the $D M$ variables for output determination, given the values of the $D M R$ variables, I estimated an output equation that included simultaneously the variables $D M_{t}, \ldots, D M_{t-3}$ and $D M R_{t}, \ldots, D M R_{t-3}$. The test statistic associated with the deletion of the four $D M$ variables from the joint equation turns out to be $F_{20}^{4}=0.2$, so that the hypothesis that actual money growth is irrelevant for output, given the inclusion of unanticipated money growth, is accepted. (Note that a test for irrelevance of a set of anticipated money-growth variables, $\widehat{D M_{t}}, \ldots, \widehat{D M_{t-3}}$, given the inclusion of the $D M R$ variables, would yield the identical test statistic.) The reverse test associated with the deletion of the four $D M R$ variables, while retaining the set of $D M$ values, yields the statistic $F_{20}^{4}=3.6$, which exceeds the 5 percent critical value of 2.9. Hence these tests reinforce the earlier results for the unemployment rate concerning the importance of the $D M R$ variables and the irrelevance of the $D M$ variables.

It should be stressed that the lag pattern of monetary effects on output shown in equation (3) refers to unanticipated money growth rather than to money growth per se. The response of output to actual values of money growth can be derived-assuming a given structure of the money-growth process, as estimated in equation (1) - by substituting into equation (3) from the condition $D M R \equiv D M-\widehat{D M}$, where $\widehat{D M}$ is given from equation (1). The resulting "reduced form" expresses output as a function of $D M_{t}, \ldots, D M_{t-5} ; F E D V_{t}, \ldots, F E D V_{t-3} ; U N_{t-1}, \ldots, U N_{t-4} ; M I L_{t}$; and $t$. With respect to monetary effects on output, the point estimates of the lag pattern turn out to be $1.04 D M_{t}+0.78 D M_{t-1}-0.27 D M_{t-2}$ $-0.17 D M_{t-3}-0.20 D M_{t-4}-0.05 D M_{t-5}$. The positive predictive role of lagged values of $D M$ in the money-growth equation (1) implies that lagged values of $D M$ in the reduced form have a net output effect that is less expansionary than the direct effect of the corresponding lagged $D M R$ value in equation (3) (because values of $\widehat{D M}$ are positively related to earlier values of $D M$ ). Accordingly, the lag of output behind actual money growth in the reduced form is shorter than that expressed in terms of unanticipated money growth in equation (3). Further, negative coefficients can appear on lagged values of $D M$ in the reduced form (in the present case from date $t-2$ onward) although the output effect of the $D M R$ values is expansionary throughout. It should also be recalled that-as pointed out in a general context by Lucas (1972) - the reduced-form expression for output as a function of $D M$ values does not have immediate implications for monetary "stabilization" policy, because any (perceived) change in "policy"- that is, in the structure of the money-growth process, 
such as a change in the reaction of $D M_{t}$ to lagged unemployment-would alter the coefficients of the reduced form. This point is already evident from the form of equation (3), which indicates that only unanticipated movements of money affect output. ${ }^{5}$

\section{Price Level Equation}

\section{A. Setup of the Price Equation}

In order to derive the form of the price equation, I begin with an expression for the demand for money,

$$
\log \left(M_{t}\right)-\log \left(P_{t}\right)=b_{0}+b_{1} \log \left(X_{t}\right)-b_{2} r_{t}+b_{3} t+\varepsilon_{t},
$$

where $M$ is the nominal money stock, $P$ is the price level (GNP deflator), $X$ is a measure of real expenditure pertinent to money demand, $r$ is a nominal interest rate (measured empirically by the Aaa corporate bond rate; see below), $t$ is a time trend, and $\varepsilon$ is a random term that is not necessarily independent of the stochastic term, $u$, in the output equation (2). The coefficients satisfy the conditions $b_{1}>0, b_{2}>0, b_{3} \gtreqless 0$, with the last coefficient reflecting any trend elements in money demand associated with the development of financial institutions, etc. The formulation in equation (5) neglects any lags in the adjustment of money demand to changes in $X, r$, etc. Although this representation is convenient, the subsequent empirical results suggest that it may be too restrictive. Hence some possibilities for lagged adjustment of money demand are considered in a later section.

The real expenditure determinant of money demand, $X$, is assumed to be linearly related to real GNP (denoted again by $y$ ) for a given value of real federal purchases of goods and services, $G$. For a given value of total GNP, an increase in $G$ reduces the volume of expenditure pertinent to money demand (especially since federal government holdings of money are excluded from the money-stock definition), so that $X$ is inversely related to $G$. I use the specification

$$
X=c(y-\gamma G),
$$

where $c>0$ and $0 \leq \gamma \leq 1$. The value $\gamma=1$ would apply if federal purchases of goods and services were entirely irrelevant to the quantity of real money demanded by the nonfederal sector. Since government purchases involve sales of equal magnitude from the nonfederal sector and since money demand would depend on the volume of both sales and purchases in this sector (with the components of GNP other than federal purchases implying both a final sale and a final purchase in the nonfederal

${ }^{5}$ However, eq. (3) is itself a partial reduced form-e.g., shifts in the variance of the money-growth process would be expected to alter the coefficients of the $D M R$ variables along the lines discussed in Lucas (1973) and Barro (1976). 
sector), ${ }^{6}$ the value $\gamma \approx \frac{1}{2}$ may be reasonable. The exclusion of state and local government purchases from the $G$ variable amounts to treating the state and local sector as comparable to the private sector in terms of money-demand behavior. (Empirically, for the period considered, it is not possible to distinguish the definition of $G$ exclusive of state and local government purchases from that inclusive of these purchases.) The present formulation also neglects any effect of government transfer activities on money demand. (Empirically, the inclusion of federal or total government transfers in the $G$ variable does not have a significant effect on the results.)

Using equations (5) and (6) and the approximation $\log (y-\gamma G) \approx$ $\log (y)-\gamma G / y$, which is satisfactory over the sample period since $\gamma G / y \ll 1$ applies, leads to the price level equation $\log \left(P_{t}\right)=$ constant $+\log \left(M_{t}\right)$ $-b_{1} \log \left(y_{t}\right)+b_{1} \gamma(G / y)_{t}+b_{2} r_{t}-b_{3} t-\varepsilon_{t}$. Substituting for $\log \left(y_{t}\right)$ from equation (2) then implies

$$
\begin{aligned}
\log \left(P_{t}\right)= & \text { constant }+\log \left(M_{t}\right)-b_{1}\left(a_{1} D M R_{t}+a_{2} D M R_{t-1}\right. \\
& \left.+a_{3} D M R_{t-2}+a_{4} D M R_{t-3}\right)-b_{1} a_{5} M I L_{t}+b_{1} \gamma(G / y)_{t} \\
& +b_{2} r_{t}-\left(b_{1} a_{6}+b_{3}\right) t-\left(\varepsilon_{t}+b_{1} u_{t}\right) .
\end{aligned}
$$

Abstracting for the moment from possible endogeneity of some of the righthand variables (notably $G / y$ and $r$ ), equation (7) implies the following hypotheses concerning monetary effects on the price level: ${ }^{7}$

1. Given current and lagged $D M R$ values (and the nominal interest rate, $r_{t}$, which would reflect anticipated inflation rates), there is a one-toone effect of $\log \left(M_{t}\right)$ on $\log \left(P_{t}\right)$. Fully perceived movements in the money stock-which correspond to changes in $M_{t}$ while holding fixed current and lagged $D M R$ values (weighted in accordance with their effects on current output) - have equiproportionate, contemporaneous effects on the price level.

2. Current and lagged values of $D M R$ have negative effects on the price level (for given values of $M_{t}, r_{t}$, etc.). The pattern of lagged $D M R$ effects corresponds, with the opposite sign, to the pattern in the output equation. If real money demand is unit elastic in real expenditure $\left(b_{1}=1\right)$, then the $D M R$ pattern in the price level equation corresponds in magnitude

6 This statement does not hold for international transactions components of GNP, which may be worth further examination in the context of demand for money. A more general discussion of the transactions measure in money-demand functions is contained in Enzler, Johnson, and Paulus (1976).

${ }^{7} \mathrm{My}$ initial inclination was to specify an equation in terms of the inflation rate, $D P_{t} \equiv$ $\log \left(P_{t}\right)-\log \left(P_{t-1}\right)$, rather than the price level. From the perspective of eq. (7), it is clear that the inflation rate would depend on the current money-growth rate, $D M_{t}$, and on changes in the $D M R$ and other variables that appear on the right-hand side of the price level equation. If the error term in eq. (7) is serially independent (or does not show strong positive serial correlation), then the error in the first-difference rate of inflation form would show strong negative serial correlation. 
and shape to the pattern in the output equation. ${ }^{8}$ More generally, the $D M R$ patterns would correspond in shape but not necessarily in magnitude.

3. Given $M_{t}$ and the $D M R$ values (and $r_{t}$, etc.), lagged values of the money stock- $M_{t-1}, M_{t-2}, \ldots$ - or, equivalently, current and lagged values of actual money growth-D $M_{t}, D M_{t-1}, \ldots$-are irrelevant to the determination of the price level.

4. In the present formulation, changes in expected inflation rates that correspond to changes in expected growth rates of money or other variables are reflected in the nominal interest rate, $r_{t}$. The relation between monetary movements and $r_{t}$ has not yet been explored. However, an increase in $r_{t}$, for given values of the $D M R$ s, etc., has a positive effect on $P_{t}$.

\section{B. Estimated-Price Equation}

Two problems with estimation of equation (7) are the endogeneity of $(G / y)_{t}$, through its dependence on $y_{t}$, and the likely endogeneity of $r_{t}{ }^{9}$ With respect to the $G / y$ variable, I have made two modifications that yield essentially equivalent results. First, I have used $G / \hat{y}$ as an instrument for $G / y$, where $\hat{y}$ is the value $\exp [\overline{\log (y)}]$ and $\overline{\log (y)}$ is calculated from the estimated-output equation (3). Second, I have changed the specification of equation (7) by replacing $G / y$ with $\log (G)$. This procedure and the previous one yield essentially the same statistical fit for the price equation and also yield similar estimates for the coefficients of the other variables. Since the estimated coefficient on the $G / y$ variable in the first approach is readily interpreted in terms of the underlying model, I report only results in this form.

With respect to the interest-rate variable (the Aaa corporate bond rate), the estimation problem would derive from correlation with the error term of equation (7). (It can be noted that this estimation problem is equivalent to the familiar one of estimating the coefficient of a nominal interest rate as one of the right-hand variables in a money-demand function.) Since I have not yet developed an analysis that relates the interest rate to exogenous variables such as money shocks, expected growth rates of money,

${ }^{8}$ Equivalently, nominal income would be invariant with the $D M R_{\mathrm{s}}$ (for given values of $M_{t}$ and $r_{t}$ ) in this case. I treat nominal income throughout as a derivative concept, implied by the underlying values of output and the price level, rather than using the (odd, but popular) approach of determining nominal income first and then considering its breakdown between output and the price level.

9 The error terms of eqq. (7) and (2) would not generally be independent, although the correlation between $\varepsilon_{t}$ (shifts in money demand) and $u_{t}$ (shifts in output) would also have to be taken into account. Surprisingly, it turns out that the estimated residuals from the two equations are not significantly correlated: the correlation is +0.15 for the residuals from eqq. (3) and (9). In general, a joint estimation of eqq. (7) and (2) could exploit any relation among the error terms, but the impact of this extension turns out to be negligible in the present case. 
and other factors, I have carried out estimation of the price equation with a lagged interest rate variable, $r_{t-1}$, used as an instrument for $r_{t} \cdot{ }^{10}$ The use of $r_{t-1}$ as an instrument would eliminate correlation between the interest-rate variable and the error term of equation (7) (thereby leading to consistent estimation at the expense of some lost efficiency) if the error term is itself serially uncorrelated. The estimation of the price equation might be improved by the development of an empirical model of interestrate determination (which I plan to work on). However, the main shortcoming of the present procedure may not be with estimation of the coefficients in equation (7) but, rather, with the lack of a full reduced-form description of the influence of money, etc., on the price level. The channels of monetary effects on prices that involve variations in the nominal interest rate are not observed when the interest-rate variable is held fixed separately, as in the present analysis.

Another possible problem with estimation of equation (7) would be correlation of the error in the money-growth equation-that is, $D M R$ with the errors in the money-demand or output equations. The first correlation could arise if the monetary authority is willing and able to "offset" shifts in money demand. The second correlation would appear if countercyclical monetary response operates with a shorter lag than that assumed in equation (1). ${ }^{11}$ (The correlation with the contemporaneous output shock would also affect the estimate of the $D M R_{t}$ coefficient in the output equation [3].) Although the present analysis does not deal with these problems, it seems that the most serious questions would arise about the estimate of the $D M R_{t}$ coefficient in equation (7). It also seems that correlation of the $D M R$ variables with the error term in equation (7) would not prejudice the results toward acceptance of the null hypotheses that were set out above.

From some preliminary work, it became clear that the immediate postWorld War II observations on the price level were heavily influenced by a residual effect of the extensive wartime controls (see below for a formal analysis of this period). Accordingly, I concentrate the empirical analysis on price equations that are estimated over the 1948-76 period. It also turned out that two additional lagged values of the $D M R$ variable, $D M R_{t-4}$ and $D M R_{t-5}$, were significant when added to equation (7), so that the reported results include the values $D M R_{t}, \ldots, D M R_{t-5}$. The $M I L$ variable, which was important in the output equation, turns out to

10 An OLS regression of $r_{t}$ on $r_{t-1}$ alone from 1948 to 1976 yields

$$
r_{t}=\underset{(0.002)}{0.001}+\underset{(0.04)}{1.01 r_{t-1}}, \quad R^{2}=.96, \quad \mathrm{D}-\mathrm{W}=1.7, \quad \hat{\sigma}=0.004 .
$$

${ }^{11}$ However, preliminary results with quarterly data suggest that biases from this source may not be serious. 
be insignificant in the price equation, and I report results separately with this variable excluded.

Table 3 contains the basic empirical results for the price equation. The results apply to annual observations for the 1948-76 period and measure $P$ by the GNP deflator (1972 base) and $r$ by the Aaa corporate bond rate. ${ }^{12}$ Results are given with the $M I L$ variable excluded or included and with the coefficient of $\log \left(M_{t}\right)$ unrestricted or constrained to equal unity, in which case $\log \left(P_{t}\right)-\log \left(M_{t}\right)$ becomes the effective dependent variable. For convenience, I write out the estimated equation (from table 3 , line 1 ) that excludes the $M I L$ variable and leaves the coefficient on $\log \left(M_{t}\right)$ unrestricted:

$$
\begin{gathered}
\log \left(P_{t}\right)=\begin{array}{c}
-4.60+1.02 \log \left(M_{t}\right)-0.74 D M R_{t}-1.48 D M R_{t-1} \\
(0.26)(0.07)
\end{array} \quad(0.17) \quad(0.21) \\
-1.79 D M R_{t-2}-1.36 D M R_{t-3}-0.72 D M R_{t-4} \\
(0.25) \quad(0.23) \quad(0.20) \\
-0.34 D M R_{t-5}+0.59(G / y)_{t}+3.7 r_{t}-0.0108 \cdot t \\
(0.16) \quad(0.14) \quad(1.1) \quad(0.0020) \\
R^{2}=.9987, \mathrm{D}-\mathrm{W}=1.8, \hat{\sigma}=0.012 .
\end{gathered}
$$

The addition of the insignificant $M I L$ variable has a negligible effect on the estimates (table 3, line 2). The results indicate absence of serial correlation in the residuals. Further, if a lagged dependent variable is added to equation (8), its estimated coefficient, $0.07, \mathrm{SE}=0.27$, differs insignificantly from zero. It also turns out that ordinary-least-squares (OLS) estimates are close to those shown in equation (8), in which $G / \hat{y}$ and $r_{t-1}$ were used as instruments. The main difference in the OLS results is a reduction in the estimated coefficients of the $G / y$ and $r$ variables, which become $0.52, \mathrm{SE}=0.11$, and $2.7, \mathrm{SE}=0.6$, respectively.

Test of a unit coefficient on $\log \left(\mathbf{M}_{\mathbf{t}}\right)$. - The estimated coefficient of the $\log \left(M_{t}\right)$ variable in equation $(8), 1.02, \mathrm{SE}=0.07$, conforms with the null hypothesis of a unit coefficient. With lagged values of the money stock excluded from equations (7) and (8) (tests of this proposition are carried out below), the hypothesis of a unit coefficient on $\log \left(M_{t}\right)$ can be viewed as a test for the absence of money illusion. In this sense this hypothesis may be regarded as being on a different level (less specific to the particular theory under test but essential for confidence in the other results) from the other propositions to be considered. Accordingly, table 3 provides estimates of price level equations in which the coefficient of $\log \left(M_{t}\right)$ is constrained to be exactly unity (which amounts to using the negative of the

12 The interest rate on prime commercial paper and the rate on savings and loan shares are insignificant when added to eqq. (8) or (9) below. 


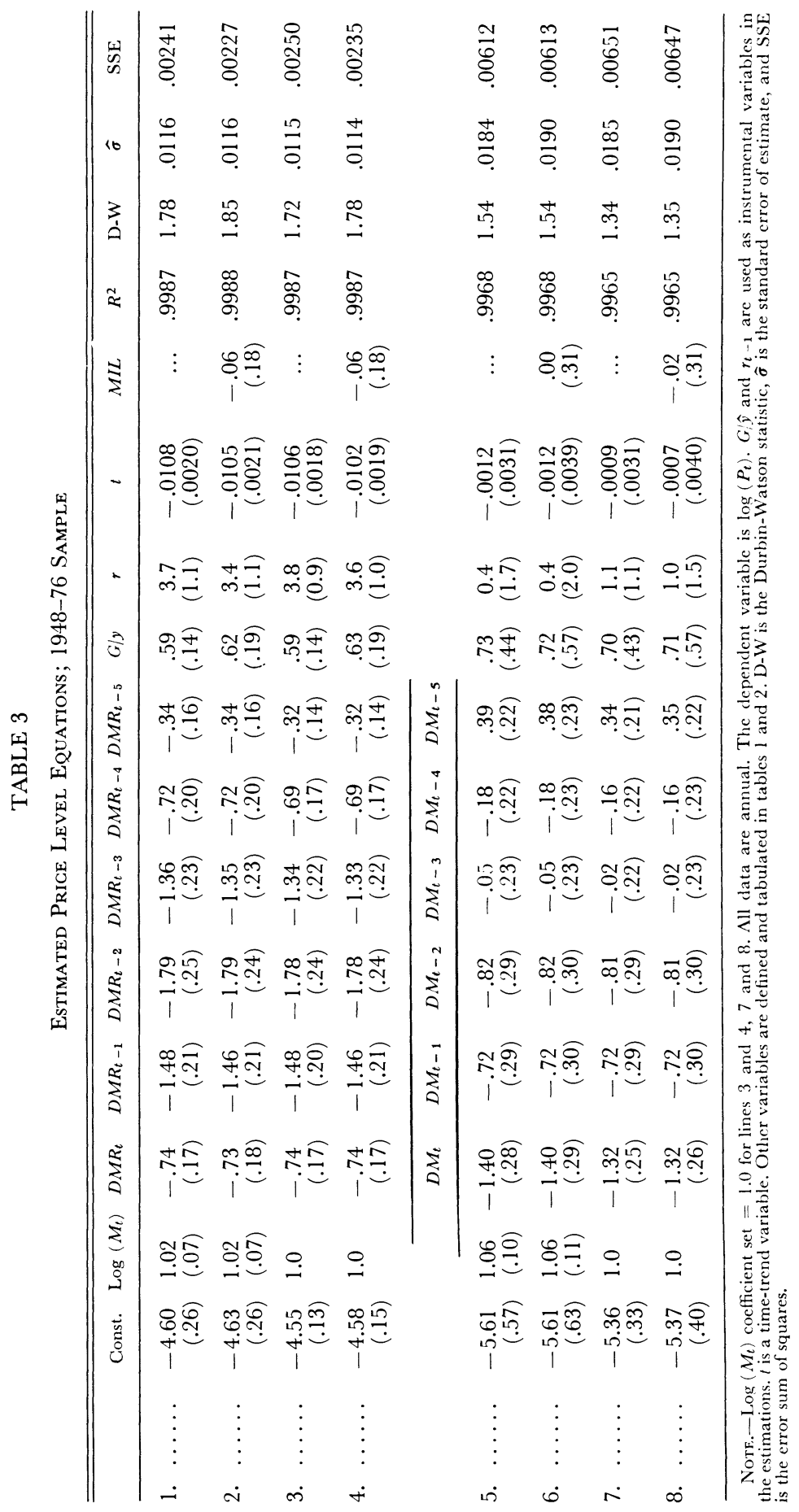


$\log$ of real money balances as a dependent variable). The estimated equation with this constraint that corresponds in form to equation (8) is, from table 3 , line 3 ,

$$
\begin{aligned}
& \log \left(P_{t}\right)=\underset{(0.13)}{-4.55}+\log \left(M_{t}\right)-\underset{(0.17)}{0.74 D M R_{t}}-\underset{(0.20)}{1.48 D M R_{t-1}} \\
& -1.78 D M R_{t-2}-1.34 D M R_{t-3}-0.69 D M R_{t-4} \\
& \text { (0.24) } \\
& (0.22) \\
& \text { (0.17) } \\
& -0.32 D M R_{t-5}+0.59(G / y)_{t}+3.8 r_{t}-0.0106 \cdot t \text {, } \\
& \text { (0.14) } \\
& \text { (0.14) } \\
& (0.9) \\
& \text { (0.0018) } \\
& R^{2}=.9987, \mathrm{D}-\mathrm{W}=1.7, \hat{\sigma}=0.012 \text {. }
\end{aligned}
$$

Again, the estimates are not materially affected by including the insignificant $M I L$ variable (table 3, line 4), and there is no indication of serial correlation in the residuals. If the lagged variable, $\log (P / M)_{t-1}$, is added to equation (9), its estimated coefficient, $0.10, \mathrm{SE}=0.21$, differs insignificantly from zero. Ordinary-least-squares estimates are again close to the instrumental estimates, except for some reduction in the estimated coefficients of the $G / y$ and $r$ variables. The OLS estimates of these coefficients are $0.50, \mathrm{SE}=0.11$, and $2.9, \mathrm{SE}=0.5$, respectively.

Estimates of DMR coefficients.-All six of the estimated DMR coefficients in equation (9) are negative - that is, conforming in sign to the underlying theory-and all are individually significantly different from zero. The precision with which the lagged response of the price level to unanticipated money growth is estimated and the smooth triangular shape of the lag pattern are striking features of the results.

In terms of quantitative correspondence to the $D M R$ lag pattern estimated in the output equation (3), it can be seen that the $D M R_{t}$ and $D M R_{t-1}$ coefficients correspond reasonably well, but the coefficients on the other lag values are much larger in magnitude in the price equation than in the output equation. The significance of the $D M R_{t-4}$ and $D M R_{t-5}$ variables in the price equation, as contrasted with their insignificance in the output equation, is one aspect of this cross-equation discrepancy. A formal comparison of the DMR coefficients from the price and output equations is carried out below.

Test for irrelevance of actual money-growth variables. - The price level equation can also be estimated with the $D M R$ values replaced by corresponding values of actual money growth, $D M$. Since $\log \left(M_{t}\right)$ is included separately as an explanatory variable, this form of the price equation amounts to regressing $\log \left(P_{t}\right)$ on $\log \left(M_{t}\right), \log \left(M_{t-1}\right), \ldots, \log \left(M_{t-6}\right)$, and the other explanatory variables. Table 3 , lines $5-8$, reports results based on the $D M$ variables. The estimated equation that uses $D M$ values but other- 
wise corresponds in form to equation (9) is, from line 7 of the table,

$$
\begin{aligned}
& \log \left(P_{t}\right)=-5.36+\log \left(M_{t}\right)-1.32 D M_{t}-0.72 D M_{t-1} \\
& \text { (0.33) (0.25) (0.29) } \\
& -0.81 D M_{t-2}-0.02 D M_{t-3}-0.16 D M_{t-4}+0.34 D M_{t-5} \\
& \begin{array}{llll}
(0.29) & (0.22) & (0.22)
\end{array} \\
& +0.70(G / y)_{t}+1.1 r_{t}-0.0009 \cdot t \text {, } \\
& \text { (0.34) (1.1) (0.0031) } \\
& R^{2}=.9965, \mathrm{D}-\mathrm{W}=1.3, \hat{\sigma}=0.019 \text {. }
\end{aligned}
$$

Two observations on the estimates are, first, that the $D M$ variables provide a much poorer fit to the price level than that obtained with the use of the $D M R$ values ( $\hat{\sigma}=0.012$ from eq. [9] vs. $\hat{\sigma}=0.019$ from eq. [10]) and, second, that the estimated pattern of coefficients in the $D M$ form is difficult to interpret.

The test for irrelevance of lagged $D M$ values in the price level equation - given the values of $\log \left(M_{t}\right)$ and the $D M R$ variables - can be carried out by running a regression of $\log \left(P_{t}\right)$ on an array of explanatory variables that includes simultaneously the two sets $D M R_{t}, \ldots, D M R_{t-5}$ and $D M_{t}, \ldots, D M_{t-5}$ and then examining the impact on the sum of squared residuals of deleting the set of $D M$ values. This procedure, for the case where the $M I L$ variable is excluded and the $\log \left(M_{t}\right)$ coefficient is constrained to equal unity, yields the test statistic $F_{13}^{6}=1.7,5$ percent critical value $=2.9 .^{13}$ Therefore the hypothesis that current and lagged values of $D M$ [and hence the values of $\left.\log \left(M_{t-1}\right), \ldots, \log \left(M_{t-6}\right)\right]$ are irrelevant to the determination of $P_{t}$-given the values of $M_{t}$ and the $D M R \mathrm{~s}$ - is accepted. A reverse test for the deletion of the six $D M R$ variables, while retaining the set of $D M$ values, yields the statistic $F_{13}^{6}=7.9$, so that the importance of the $D M R \mathrm{~s}$ (and the empirical distinction between the $D M R$ and $D M$ concepts) is confirmed by this test. The same conclusions obtain if the $M I L$ variable is included and if the $\log \left(M_{t}\right)$ coefficient is unrestricted. A simultaneous test that the coefficient of the $\log \left(M_{t}\right)$ variable is unity and that the set of $D M$ variables is irrelevant, which involves a test of seven coefficient restrictions, yields the statistic (with the $M I L$ variable excluded) $F_{12}^{7}=1.7$, which is below the 5 percent critical value of 2.9. (A simultaneous test that the $\log \left[M_{t}\right]$ coefficient is unity and that the $D M R$ variables are irrelevant yields $F_{12}^{7}=7.2$.) The acceptance of the joint hypothesis that the $\log \left(M_{t}\right)$ coefficient is equal to unity and that the set of $D M$ variables is irrelevant is important, because it implies acceptance of the basic hypothesis that perceived movements in the money stock-that is,

\footnotetext{
13 In the context of instrumental estimates, this critical value is only an approximation.
} 
changes in $M_{t}$ with the $D M R$ values and $r_{t}$ held constant-imply equiproportionate, contemporaneous movements in the price level.

Estimates of other coefficients in the price equation.-The estimated coefficient of the $G / y$ variable in equation (9), $0.59, \mathrm{SE}=0.14$, is positive, significantly different from zero, and in the vicinity of the plausible value of $\frac{1}{2}$ (assuming a unit income elasticity of money demand, $b_{1}$ : see below). The tabulation of this variable in table 2 indicates that the movement of $G / y$ (which is based on federal purchases of goods and services-a concept that is dominated by defense expenditure) has been downward since 1968. The drop in $G / y$ from 0.12 in 1968 to 0.08 in 1976 implies, according to the estimated coefficient from equation (9), that the 1976 price level is about 2.5 percent lower than it would have been if $G / y$ had remained at its 1968 level. The other important movement of $G / y$ during the sample period is the sharp increase with the start of the Korean War in 1951, followed by a strong decrease from 1953 to 1955 . The 1951 movement of federal expenditure implies, on this count, an estimated price level increase from 1950 of about 3 percent (although the estimated price level for 1951 is still about 1.5 percent below the actual value). The expenditure decline from 1953 to 1955 implies, on this count, a price level decrease by about 3 percent.

The point estimate of the interest-rate coefficient in equation (9) implies a money-demand elasticity of -0.19 at the sample mean of $r$ over the 1948-76 period and an elasticity of -0.32 at the 1976 value of $r$. It should be noted that the interest-rate variable is important for "explaining" some of the recent movements in the price level. For example, the rise in the interest rate from 0.074 in 1973 to 0.086 in 1974 "accounts for" 0.046 out of the total price level increase of 0.095 for 1974 . It is likely that the interest-rate movements reflect changes in anticipated inflation, but the present analysis does not make that connection explicit.

The estimated time trend, $-0.011, \mathrm{SE}=0.002$, is significantly negative, but only 1.1 percent per year in magnitude. Since the estimated timetrend coefficient in the output equation (3) is 0.035 , it follows from the forms of equations (5) and (7) that the estimates imply a negative trend in the demand for money over the 1948-76 period of about 2.4 percent per year (assuming a unit income elasticity of money demand, $b_{1}$ : see below). It would be preferable to relate this trend to movements in variables that explicitly measure changes in financial structure or other forces, especially since the stability of the relation between money demand and time per se is doubtful. However, I have not made any progress along these lines.

As mentioned above, the estimated coefficient of the $M I L$ variable is insignificant throughout (table 3, lines 2, 4, 6, 8), although the standard error of about 0.2 in the DMR equations is substantial. This result contrasts with the significant, positive coefficient on the $M I L$ variable that was obtained in the output equation $(3)(0.55, \mathrm{SE}=0.09)$. In light of the 
discussion of the military variable in Part II above, the insignificant effect on the price level does more to provide further doubt about the meaning of the estimated effect on output rather than to question the price level results.

Cross-equation tests of coefficients in the price and output equations.-As noted above, the pattern of estimated DMR coefficients in the price equation appears to differ from that in the output equation. A formal test of correspondence of these two sets of coefficients involves, first, a joint estimation of the output and price equations subject to the constraint that the $D M R$ coefficients be of opposite sign and equal magnitude aside from multiplication by the income elasticity of money demand, $b_{1}$, in equation (7) and, second, a comparison by means of a likelihood ratio test of the residuals in the constrained calculation with those from the unconstrained case. The constrained estimates are determined from a nonlinear three-stage leastsquares routine (from the TSP regression package), which also provides estimates of the variances and contemporaneous covariance of the error terms across the output and price equations. In the present circumstance this covariance turns out to be negligible (n. 9 above). For purposes of carrying out a likelihood ratio test, the estimates that omit constraints on the coefficients have also been obtained from the joint procedure that includes estimates of the variances and contemporaneous covariance of the error terms. In the present context, the output and price level equations are both estimated over the 1948-76 period with $D M R_{t}, \ldots, D M R_{t-5}$ used as explanatory variables. The military variable has also been included in both equations. In one set of calculations, a separate military coefficient was estimated for the price and output equations in both unconstrained and constrained forms, while in another set the two military coefficients were restricted in the constrained form, along with the $D M R$ variables, to have coefficients in the two equations that were of opposite sign and of equal magnitude except for multiplication by $b_{1}$ in equation (7). Since the size of the estimated $M I L$ coefficient is much higher in the output equation than in the price equation, it would be anticipated that the null hypothesis of corresponding coefficients across the two equations is less likely to be accepted when the restriction on the MIL coefficients is included as part of the null hypothesis.

The basic outcome of the cross-equation test is that the null hypothesis of consistent $D M R$ coefficients in the output and price level equations is rejected at the 5 percent level. For example, for the case where the coefficient of $\log \left(M_{t}\right)$ in the price equation is restricted to equal unity (results are similar if this coefficient is unrestricted) and the coefficients of the two $M I L$ variables are left unrestricted throughout, the likelihood ratio implies the test statistic, which is distributed asymptotically as a $\chi^{2}$ variable with degrees of freedom equal to the number of coefficient restrictions (in 
this case 5), of 19.1, which exceeds the 5 percent critical value of $11.1 .^{14}$ For the case where the two $M I L$ coefficients are also constrained as a part of the null hypothesis, the test statistic is 41.1 , which is well above the 5 percent critical value with 6 degrees of freedom of 12.6 .

Lagged adjustment of money demand.-The statistical tests above support the impression from equations (3) and (9) that the pattern of price level response to the $D M R$ variables is drawn out relative to the output response. From the perspective of the underlying model, an obvious possibility for "explaining" this behavior would be to modify the form of the moneydemand function, as expressed in equations (5) and (6), to allow for some dependence of $\log (M / P)_{t}$ on lagged values of the explanatory variables$\log (y), G / y$, and $r$. However, the most common form of partial adjustment, which would amount to introducing $\log (M / P)_{t-1}$ as an additional determinant of current money demand, would not account for the results. This form would rationalize the inclusion of the lagged variable, $\log (P / M)_{t-1}$, in the price equation (7). However, as noted above, the estimated coefficient of this variable differs insignificantly from zero. Put another way, this form of partial adjustment implies that $\log \left(P_{t}\right)$, relative to $\log \left(M_{t}\right)$, would depend on a distributed $\operatorname{lag}$ of $\log (y), G / y$, and $r$, which implies not only an elongated response of the price level to the $D M R$ variables but also a dependence of the current price level on lagged values of $G / y$ and $r$ (and $M I L)$. In fact lagged values of $G / y$ and $r$ (and $M I L$ ) are insignificant when added to equation (7) (in an OLS regression), which is consistent with the insignificant effect of the $\log (P / M)_{t-1}$ variable that was referred to above.

A form of partial adjustment that can account for the cross-equation results involves a special response of money demand to temporary movements in income, as stressed by Darby (1972). Consider the division of $\log \left(y_{t}\right)$ from equation (2) into a "temporary" component, $\log \left(y_{t}^{\tau}\right)=$ $a_{1} D M R_{t}+a_{2} D M R_{t-1}+a_{3} D M R_{t-2}+a_{4} D M R_{t-3}+u_{t}$, and a "permanent" component, $\log \left(y_{t}^{P}\right)=a_{0}+a_{5} M I L_{t}+a_{6} t$. Suppose that temporary income has a strong effect on current money demand that dissipates only gradually in accordance with an adjustment parameter, $\lambda$. In this case a modified form of the money-demand function would be $\mathrm{b}^{15}$

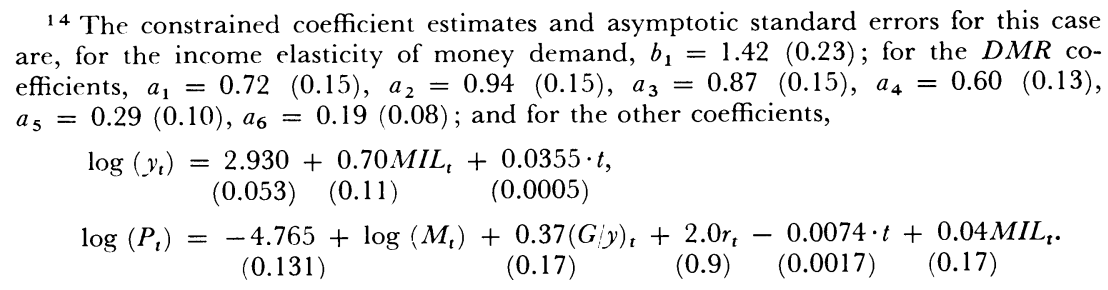

15 The $G / y$ and $M I L$ variables are treated as "permanent" elements in this specification. 


$$
\begin{array}{r}
\log \left(M_{t}\right)-\log \left(P_{t}\right)=b_{0}+b_{1}\left[\log \left(y_{t}^{P}\right)-\gamma(G / y)_{t}\right]-b_{2} r_{t}+b_{3} t \\
+b_{4}\left[\log \left(y_{t}^{\tau}\right)+(1-\lambda) \log \left(y_{t-1}^{\tau}\right)+(1-\lambda)^{2} \log \left(y_{t-2}^{\tau}\right)+\ldots\right] \\
+\varepsilon_{t}, \quad(11)
\end{array}
$$

where $0 \leq \lambda<1, b_{1}$ is the elasticity of money demand with respect to permanent income, and $b_{4}$ is the elasticity with respect to current temporary income. ${ }^{16}$

From the definitions above of $\log \left(y_{t}^{P}\right)$ and $\log \left(y_{t}^{\tau}\right)$, equation (11) can be used to obtain a price equation that generalizes equation (7),

$$
\begin{aligned}
\log \left(P_{t}\right) & =\mathrm{constant}+\log \left(M_{t}\right)-b_{4}\left\{a _ { 1 } \left[D M R_{t}+(1-\lambda) D M R_{t-1}\right.\right. \\
& +\ldots]+a_{2}\left[D M R_{t-1}+(1-\lambda) D M R_{t-2}+\ldots\right]+a_{3}\left(D M R_{t-2}\right. \\
& \left.+\ldots)+a_{4}\left(D M R_{t-3}+\ldots\right)\right\}-b_{1} a_{5} M I L_{t}+b_{1} \gamma(G / y)_{t}+b_{2} r_{t} \\
& -\left(b_{1} a_{6}+b_{3}\right) t-\varepsilon_{t}-b_{1}\left[u_{t}+(1-\lambda) u_{t-1}+\ldots\right] .
\end{aligned}
$$

Accordingly, each variable $D M R_{t-i}$ is now replaced by a distributed lag, $D M R_{t-i}+(1-\lambda) D M R_{t-i-1}+\ldots$ It is also apparent from equation (12) that values of $\lambda$ below one will generate, at least qualitatively, the observed pattern of behavior in which the price level response to $D M R$ values is elongated relative to the output response. Moreover, in this formulation it is only the contemporaneous values of $G / y, r$, and $M I L$ that would affect the current price level. ${ }^{17}$

The output and price level estimates can now be examined for crossequation consistency from the standpoint of the output equation (2) and the modified price equation (12). Since $b_{4}$ and $\lambda$ have to be estimated (by means of the nonlinear three-stage least-squares procedure), there are now only two restrictions corresponding to the imposition of a common set of coefficients, $a_{1}, \ldots, a_{4}$, across the two equations. However, the form of equation (12) for the price level implies two additional restrictions relative to the form in equation (9), which permitted unrestricted coefficient estimates on $D M R_{t}, \ldots, D M R_{t-5}$. (Lagged values only up to $D M R_{t-5}$ are also used in the restricted form.) The basic finding is that the results

16 The log-linear form is solely for algebraic convenience. Darby's (1972, pp. 929-30) discussion suggests that a different functional form may be more appropriate for relating "transitory money demand" to "transitory income." However, the log-linear representation seems adequate to account for the present empirical results.

17 The error term in eq. (12) would show positive serial correlation if $0 \leq \lambda<1$ and $\varepsilon_{t}$ and $u_{t}$ are serially independent. In fact the estimated residuals from the price equation (9) do not exhibit serial correlation. One possible explanation is that the $u_{t}$ part of "transitory income" does not have the distributed lag effect on money demand that is postulated in eq. (11). It is also necessary to reconcile the lack of correlation between the residuals of eqq. (3) and (9) (n. 9 above) and the lower value of $\widehat{\sigma}$ from the price equation (9) than that in the output equation (3). In the context of the forms of the error terms in eqq. (2) and (12), these results require strong negative correlation between the output shift $\left(u_{t}\right)$ and the money-demand shift $\left(\varepsilon_{t}\right)$. 
are in accord with these restrictions. For the case of a unit coefficient on $\log \left(M_{t}\right)$ (and where no cross-equation restriction is imposed on the MIL coefficients), ${ }^{18}$ the likelihood ratio implies a test statistic of 5.1, which is below the 5 percent critical value for the $\chi^{2}$ distribution with 4 degrees of freedom of 9.5. Hence the generalization of the money-demand function does reconcile the apparent conflict between the output and price level responses to the $D M R$ values. The full set of constrained estimates and asymptotic standard errors is

Current temporary income elasticity of money demand:

$$
b_{4}=0.85, \mathrm{SE}=0.13,
$$

adjustment parameter: $\lambda=0.40, \mathrm{SE}=0.07$,

common DMR coefficients: $a_{1}=0.98, a_{2}=1.15, a_{3}=0.68, a_{4}=0.24$,

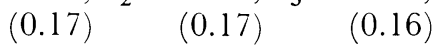

$$
\begin{aligned}
& \log \left(y_{t}\right)=2.942+0.58 M I L_{t}+0.0355 \cdot t\left(R^{2}=.9975, \mathrm{D}-\mathrm{W}=1.9\right) \text {, } \\
& \begin{array}{lll}
(0.047) & (0.10) \quad(0.0004)
\end{array} \\
& \log \left(P_{t}\right)=-4.641+\log \left(M_{t}\right)+0.47(G / y)_{t}+3.0 r_{t} \\
& (0.115) \quad(0.15) \quad(0.8) \\
& -0.0092 \cdot t+0.01 M I L_{t}\left(R^{2}=.9986, \mathrm{D}-\mathrm{W}=1.8\right) \text {. } \\
& (0.0015) \quad(0.15)
\end{aligned}
$$

The estimates for $a_{1}, \ldots, a_{4}$, together with the values for $b_{4}$ and $\lambda$ and the form of equation (12), imply that the estimates for the $D M R_{t}, \ldots$, $D M R_{t-5}$ variables in the unrestricted form of the price equation (9) should be $-0.83,-1.48,-1.46,-1.08,-0.65$, and $-0.39 .{ }^{19}$ As suggested by the likelihood ratio test statistic above, these figures accord well with the unrestricted estimates shown in equation (9).

In one sense these results indicate conformity between the output and price level coefficient estimates in the context of a perhaps plausible moneydemand representation that allows for gradually dissipating effects of temporary income (with an adjustment coefficient, $\lambda$, on the order of 0.4 per year). On the other hand, the admission of partial adjustment in the money-demand function-while possibly theoretically and empirically warranted-substantially weakens the discriminatory power of the crossequation tests. Since the utilized form of adjustment is only one of many possible specifications and since the chosen form was dictated more by prior empirical results than from ex ante theorizing, it seems clear that these results do not provide strong support for the underlying model.

\footnotetext{
18 A cross-equation restriction would arise here only if the value of $b_{1}$ or $\gamma$ were specified ex ante. For plausible values of $b_{1}$ or $\gamma$, it still seems that the output effect of the $M I L$ variable is unduly large relative to the price level effect.

${ }_{19}$ The $D M R_{t-6}$ cocfficient would be -0.23 . If this variable is added to eq. (9), its (stimated coefficient is $-0.15, \mathrm{SE}=0.16$.
} 
Rather, the results have a more modest interpretation - that cross-equation inconsistency would not be a basis for rejecting the model.

Lagged response of the price level to money movements. - As in the case of the output equation, the effects of lagged money growth on the price level have been expressed in terms of $D M R$ values rather than $D M$ values. The response of $\log \left(P_{t}\right)$ to current and lagged values of money can be derivedagain assuming the stability of the money-growth process, as estimated in equation (1) - by using the condition $D M R \equiv D M-\widehat{D M}$, where $\widehat{D M}$ is determined from equation (1). (This procedure holds fixed the nominal interest rate, $r_{t}$, and therefore misses any monetary effects on the price level that operate through interest-rate variations. The $G / y$ variable is also held fixed in this analysis.) Substituting for the DMR values in equation (12) and using the joint coefficient estimates listed in equation (13) leads to the following point estimates of the reduced-form lag effects from the money stock to the price level (which is equivalent to the lag effects from actual money growth, $D M$, to the inflation rate) $:{ }^{20} 0.17 \log \left(M_{t}\right)-0.31$ $\log \left(M_{t-1}\right)+0.46 \log \left(M_{t-2}\right)+0.51 \log \left(M_{t-3}\right)+0.27 \log \left(M_{t-4}\right)+$ $0.00 \log \left(M_{t-5}\right)-0.03 \log \left(M_{t-6}\right)-0.03 \log \left(M_{t-7}\right)+0.01 \log \left(M_{t-8}\right)$. Two important observations about this lag pattern are, first, that there is at most a weak near-term positive link between the money stock and the price level and, second, that there is a long lag-in the 2- to 4-year rangein the main positive effect of money on the price level. ${ }^{21}$ With regard to the first observation, a point to stress is that this weak near-term link between money and prices is consistent with the property that anticipated money movements are reflected in one-to-one, contemporaneous movements of the price level. This basic hypothesis-associated with a unit coefficient on $\log \left(M_{t}\right)$ and with the irrelevance of the $D M$ variables in the price equation - has already been accepted for the equation that yielded the pattern above of reduced-form lag effects from money to prices. ${ }^{22}$ The long lag in the response of the price level to money movements can be "explained" from two elements - first, the dependence of output on lagged values of the $D M R$ variable, which would itself produce about a 2-year lag of prices behind money, and, second, the dependence of money demand on lagged values of temporary income, which lengthens the lag to the 2- to 4-year range.

20 This calculation does not terminate with the $D M R_{t-5}$ value but, rather, includes the full distributed lag implied by the form of eq. (12).

${ }^{2}$ Similarly long lags in the impact of (actual) money movements on the price level have been noted by Selden (1976, p. 5) and Gordon (1975, p. 647).

22 Hence Gordon's criterion (1975, p. 615), "Is the effect of money on prices instantaneous, as required by the rational-expectations literature, or does it operate with a long lag ?" does not make sense. The effect of anticipated money movements on the price level can be virtually instantaneous at the same time that unanticipated movements (and hence actual movements of money in a reduced form that holds fixed the predictors of money growth) affect the price level only with a long lag. 
Pre-1948 observations and the residual effect of wartime price controls.-The hypothesis that price level observations from the immediate post-World War II period are generated from the same model that generated the observations from 1948 to 1976 can be decisively rejected. For example, for the case where the coefficient of $\log \left(M_{t}\right)$ is constrained to equal one and the $M I L$ variable is excluded (changes in these features are unimportant in the present context), the test statistic for including the 1946-47 observations in equation (9) is $F_{19}^{2}=55.5,5$ percent critical value $=3.5$; while that for the 1945-47 observations is $F_{19}^{3}=83.2,5$ percent critical value $=3.1$. An extrapolation of the price level estimates from equation (9) to the 1945-47 years (table 2, cols. 2, 3) shows that the equation overestimates the reported price level by about 7.5 percent in 1947, 19 percent in 1946, and 42 percent in 1945.

On the other hand, an output equation of the form of equation (2) can satisfactorily encompass the 1945-47 observations. The test statistics are $F_{22}^{2}=0.2,5$ percent critical value $=3.4$, for the inclusion of the 1946-47 observations; and $F_{22}^{3}=0.9,5$ percent critical value $=3.0$, for the 1945-47 observations. ${ }^{23}$

A possible interpretation of the price level and output results for 1945-47 is that the controls, which were gradually eased from 1946 on, principally affected the reported price level without having real effects on output, the economically relevant price level, etc. Under this interpretation, the extrapolation of the post-1948 estimated price equation to the 1945-47 period (table 2, col. 2) may provide better estimates than the reported price indices of the economically relevant price level for these years. According to this approach, the reported price increase by 14.5 percent from 1945 to 1946 would be converted to a price decrease of 9 percent, the reported price increase by 12.5 percent from 1946 to 1947 would be converted to an increase of 1 percent, and the reported price increase by 6.5 percent from 1947 to 1948 would be converted to a decrease of 0.5 percent.

Price controls in the post-1948 period.- The two instances of general pricecontrol programs since 1948 are the Korean War controls for 1951-52 and the more recent experiment from August 1971 through roughly 1973. (I exclude the wage-price guideposts episode from 1962 to roughly 1966 as being a priori nonserious, although the within-sample residuals from equation [9] are -1.1 percent for 1962 and -0.6 percent for 1963.) The within-sample residuals from equation (9) (table 2, col. 3) for the five "control years" 24 are +1.6 percent for $1951,+0.1$ percent for 1952,

${ }^{23}$ Using extrapolations of the money-growth equation back to 1937 to form the required $D M R$ values, it appears that the output equation is stable at least back to 1941 . The price level equation, which substantially overestimates the reported price level for 1943-44, appears to be roughly back on track in 1942. The unemployment rate equation is stable back to 1942 but substantially underestimates the actual value in 1941 .

${ }^{24}$ I have included the 1971 observation with this group, although it could be argued that this observation is affected by expectations of controls prior to August, which might raise the reported average price level for the year. 
+1.3 percent for 1971, +0.3 percent for 1972, and 0.0 percent for 1973 . More interestingly for the present purpose, if an extrapolation to the 5 control years is made from a relation of the form of equation (9) that is estimated only over the "noncontrol years," 1948-50, 1953-70, and 197476 , the residuals are +3.9 percent for $1951,+1.9$ percent for $1952,+1.2$ percent for 1971, -0.3 percent for 1972, and -1.3 percent for 1973 . A similar pattern of residuals obtains if the extrapolation is from the 1948-50, 1953-70 sample. An extrapolation from the 1948-70 sample yields the residuals: +2.8 percent for $1971,+0.7$ percent for 1972 , and 0.0 percent for 1973. Hence there is no indication from these calculations of a downward effect of controls on the price level.

Considering the pattern of residuals above, it seems unnecessary to carry out a formal $F$-test of the hypothesis that controls lower the reported price level. (Such a test is carried out in an earlier version of this paper: Barro 1977b.) However, it is worth noting two difficulties with price-control analyses that are based either on extrapolated residuals or on an $F$-test for a shift in the parameters of a price equation. (See Oi 1976 for some additional issues in this context.) First, the extent and probability of controls is unlikely to be exogenous with respect to shifts in the price equation. (This interconnection might explain the apparently strong, perverse effect of controls during the Korean War, although the large wartime increase in the $G / y$ variable is already held constant in the price equation.) If controls are an indicator of a positive shift in the price equation, then the tests would be biased toward rejecting the hypothesis that controls lower the price level. Second, the present type of test neglects the possible impact of controls on the right-hand variables of the price equation. The present analysis would reveal only the effects of controls for given values of the explanatory variables. In particular, it would be worth examining the possible effect of controls on the interest rate, although that investigation will require an extension of the analysis to interest-rate determination. Despite these caveats, it is difficult to see how the post-1948 experience can be used to argue that controls significantly depress the price level, ${ }^{25}$ even if one abstracts from the distinction between the reported and actual price levels during a controls period.

Post-1974 behavior of money demand.-It is worth examining whether the estimated-price equation shows any indication of the post-1974 breakdown in the money-demand function that has been noted by Enzler et al. (1976), Goldfeld (1976), and others. The within-sample residuals from equation (9) (table 3, col. 2) for 1974-76 are -0.3 , +0.9, and -0.2 percent, respectively. If a relation of the form of equation (9) is fitted only

25 This conclusion seems to agree with that reached by Feige and Pearce (1976, p. 295) and to conflict with results obtained by Gordon (1975, p. 640). However, it is difficult to make a satisfactory comparison with Gordon's results, because his measurement of the price level by the private deflator exclusive of food and energy components involves a mixing up of absolute and relative price movements. 
through 1973, the extrapolated residuals for 1974-76 are $0.0,+1.5$, and +0.3 percent, respectively. A test for unchanged structure for 1974-76 yields the statistic $F_{16}^{3}=0.8$, which is well below the 5 percent critical value of 3.2. Hence the results do not support the hypothesis of a structural break in money demand after 1974. This conclusion is in accord with recent money-demand estimates reported by Hamburger (1977). The difference in Hamburger's and my results from those in the studies above may derive from the use of a long-term rather than a short-term interest rate. At a theoretical level, the long-term interest rate could be more pertinent than the short-term rate to money demand even if short-term assets were the closer substitute for money. Since the long rate would represent a weighted average of anticipated future short rates, it would affect current money demand if there were lump-sum, investment-type costs associated with changing average holdings of cash through changes in the timing of transactions, shifts to new types of assets, etc.

\section{Predictions}

Predictions for 1977 onward of money growth, output, and the price level (and the rate of inflation) are contained in tables 1 and 2. The moneygrowth-rate predictions assume that federal expenditure relative to normal, FEDV, remains at its 1976 level $^{26}$ and that unemployment rates from 1977 on correspond to the predictions from an updating of my earlier study (Barro 1977a, p. 102). The predicted values for money growth (table 1, col. 2) are 5.8 percent for 1977 and 6.7 percent for 1978, rising from there to a long-run predicted value of 7.0 percent per year. This high longrun prediction for the money-growth rate reflects the response of $D M$ to the lagged unemployment rate (eq. [1] above), combined with an estimate of the current and future "natural" unemployment rate in the vicinity of 6.5 percent. Even if this unemployment-rate estimate is correct, the response of money growth in the circumstance of a permanently high level of the unemployment rate may not conform to the countercyclical response that was estimated in equation ( 1 ) over a sample period where the natural rate was, in the main, much lower than 6.5 percent. Although presently I do not have a better procedure for forecasting money growth, it is important to recognize that inflation-rate forecasts are sensitive to these forecasts for money growth. (However, the output predictions, which are based on $D M R$ values, are not sensitive in the same way to the money-growth projections.)

With respect to output predictions (table 1, col. 5), note first that the

\footnotetext{
26 Since the $F E D V$ variable has not been normalized to make its average value equal to zero in the context of secular growth of the public sector, this value for FEDV (0.18) is positive. Normalization of the $F E D V$ variable would affect none of the substantive results.
} 
1976 value of actual output relative to trend, $\widetilde{\log (y)}$, is -5.4 percent, as compared with an estimated value of -6.5 percent. For the forecast period (assuming that the values of the $M I L$ variable and all future $D M R \mathrm{~s}$ are equal to zero), the predictions for output relative to trend implied by the estimated equation (3), which are labeled $\mathrm{A}$ in table 1 , are -5.6 percent for 1977, -4.2 percent for 1978, - 3.5 percent for 1979, and -3.2 percent for 1980 onward. (The negative estimate of the long-run value for $\widehat{\log [y]}$ is implied by the assumed zero value for the military variable, in contrast to the positive value of this variable that prevailed over most of the sample period.) Predictions based on the jointly estimated coefficients that are shown in equation (13), which are labeled B in table 1 , are basically similar. The prediction pattern reflects the gradual decay in influence of the contractionary monetary behavior (negative values of $D M R$ ) from 1974-76. In terms of forecasts for growth rates of real GNP, the implied values based on equation (3) are 3.4 percent for 1977 (using the actual value of 1976 output as a base)-which is just under the trend rate of growth-4.9 percent for 1978, 4.3 percent for 1979, 3.8 percent for 1980, and 3.5 percent-- the estimated trend rate of growth--for 1981 and beyond.

Two sets of price level and inflation-rate predictions are shown in table 2. Projection $\mathrm{A}$ uses the coefficients from the estimated price equation (9), while projection B utilizes the jointly estimated coefficients that are shown in equation (13). Both projections assume that the $G / y$ and $r$ variables remain at their 1976 levels and that values of $D M R$ from 1977 on are equal to zero. The largest difference in the two projections occurs for the 1977 forecast-projection A implies a 7.3 percent inflation rate, while projection $\mathrm{B}$ yields only a 6.3 percent rate. Both projections show some tapering off of inflation to 1980 - to just above 4 percent per year in the first case and just below 5 percent per year in the second. Finally, both projections imply some increase in the inflation rate after 1980 - to a longrun value of 5.9 percent per year in the first case and 6.1 percent per year in the second. These long-run values are implied by the long-run prediction for money growth of 7.0 percent per year, together with an estimated time trend in the price equation of -1.1 and -0.9 percent per year, respectively.

\section{A Simulated "Phillips Curve"}

The present results on money growth, output, and the price level and the earlier results on the unemployment rate can be combined to describe some aspects of the dynamics of economic response to monetary disturbances. This description amounts to tracing out a dynamic Phillips curve in which temporary movements of output and the unemployment rate relative to "normal" values are associated with departures of the price 
level and inflation rate from their normal values. The main features of this analysis can be illustrated from an exercise in which there is an initial "steady state" (produced, say, by a long series of zero $D M R$ values) that is disturbed in year 0 by a positive money shock, say, $D M R=0.01$. Subsequent money shocks are assumed to be absent (i.e., $D M R=0$ for year 1 onward) and changes in other "exogenous" variables such as $r,{ }^{27}$ $M I L$, and $G / y$ are also not considered.

The behavior of money growth is assumed to be described by equation (1) and that of output and the price level by the jointly estimated coefficients shown in equation (13). The unemployment rate (which enters in the determination of anticipated values of $D M$ in eq. [1]) is based on an updated form of the equation from my earlier study (Barro 1977a, p. 108). ${ }^{28}$ Table 4 indicates the resulting time pattern of estimated values for $D M, \log (M), U, \log (y), D y$ (the growth rate of output), $\log (P), D P$ (the inflation rate), $\log (y)+\log (P)$ (nominal GNP), and $D y+D P$ (the growth rate of nominal GNP) - all expressed as deviations from normal or trend values.

The positive money shock in year 0 produces an expansion that is concentrated in years $0-2$ in terms of a higher level of output and a lower rate of unemployment and in year 0 in terms of a higher growth rate of output. The level of output is most of the way back toward normal by year 3 and completely back by year 4 . By implication, the growth rate of output is below normal in years $2-4$. The unemployment rate is back to its natural value by year 3 .

The price level, which is raised slightly above its normal trend in year 0 , actually falls below this trend for years 1 and 2. The price level moves above trend in year 3 and strongly above trend in years 4-6. Correspondingly, the inflation rate is above normal in year 0 , well below normal in year 1 , about normal in year 2 , and well above normal in years $3-5$. In the present example, the price level remains permanently above trend (corresponding to the permanent shift above trend in the money stock), but the inflation rate returns asymptotically to its normal value.

The last two columns of table 4 indicate the implications of the output and price level paths for the level and growth rate of nominal GNP. Nominal GNP rises strongly along with real GNP in year 0 but declines in years 1-3. Nominal GNP grows from year 4 on along with the increases in the price level.

The simulation illustrates the sense in which a temporary economic high

${ }^{27}$ Clearly, endogenous movements of the nominal interest rate could be occurring, although the use of a long-term (Aaa corporate bond) rate makes the assumed constancy of $r$ more plausible in the present example.

28 The pattern of $D M R$ coefficients in this equation is $-6.5 D M R_{t}-11.7 D M R_{t-1}-$ $5.5 D M R_{t-2}$. The estimated natural unemployment rate for 1976 from this equation is 6.7 percent. 


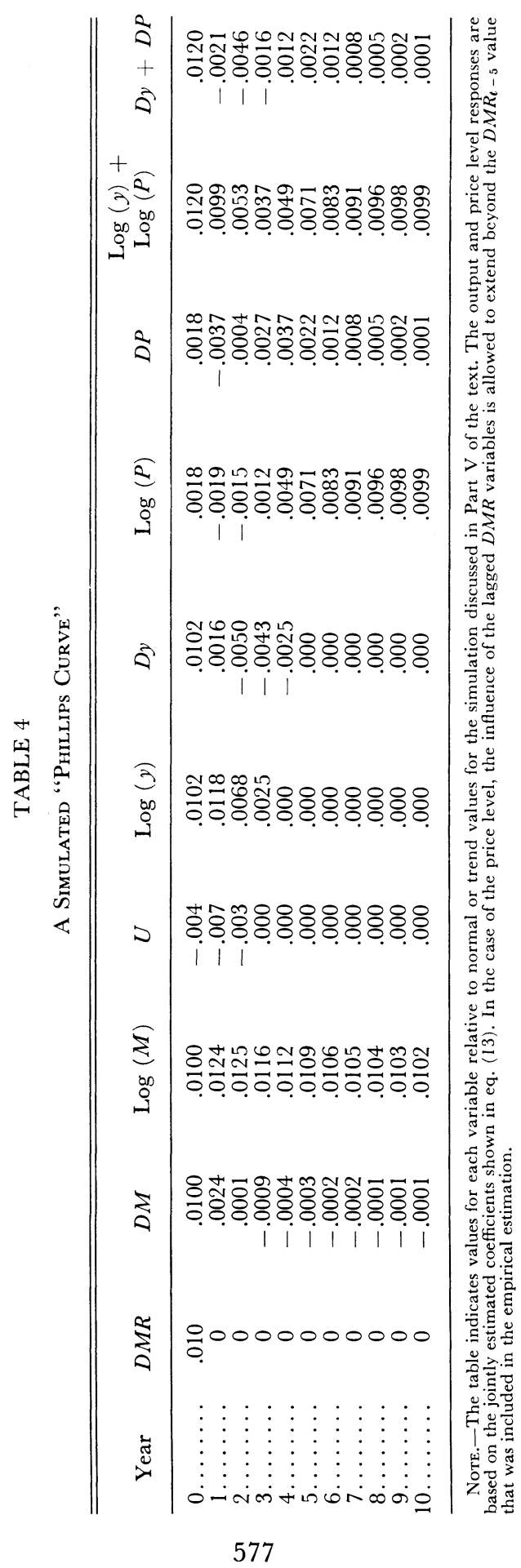


(principally in years 0-2) produced by an unanticipated monetary expansion is associated with a delayed (from year 3 on) temporary increase in the inflation rate and a somewhat further delayed (especially from year 4 on) but permanent increase above trend in the price level.

It is not appropriate to view the type of dynamic interplay between output and prices that is described in table 4 as a menu for a policy tradeoff. Some fallacies in this view have been pointed out in Lucas (1972), Sargent and Wallace (1975), Barro (1976), et al. At the risk of repetition, a principal point is that the monetary stimulus assumed in table 4 must be unanticipated, so that perceived changes in systematic policyfor example, shifts in the extent of feedback from the unemployment rate or other variables to the money-growth rate-would not produce the output and unemployment-rate responses that are shown in the simulation.

A different viewpoint, exemplified by Taylor (1975), is that unanticipated monetary changes can be engineered by the monetary authority in a systematic, presumably countercyclical manner. ${ }^{29}$ This approach assumes, first, that individuals do not appreciate that the monetary authority is pursuing a policy of systematic deception (which could produce an unstable situation) and, second, that the private sector is in a reactive position vis-à-vis an activist, independent policymaker. Under these two conditions, the private sector is naturally viewed as adapting its expectations gradually (perhaps along Bayesian lines) to shifts in policy. An alternative perspective on policy is that it reflects the views of the private sector, as channeled through the political process, with respect to such basic issues as being on or off the gold standard, whether or not to establish a central monetary authority like the Federal Reserve, whether to pursue a "Full Employment Act" economic policy or a steady money-growth policy, etc. In this view the basic structure of monetary determination is likely to be stable over long periods (as I believe is true as a good approximation in the United States for the post-World War II period and is probably also true for the gold standard period from 1880 to 1914), although the process would be subject to infrequent, discrete changes. Examples of such changes for the United States would seem to be the return to gold in 1879, the establishment of the Federal Reserve in 1914, the changes in the role of gold during World War I and in 1933, and the passage of the Full Employment Act in 1946. It remains to be seen whether the recent heightening of attention to the amount and stability of the money-growth rate will pro-

${ }^{29}$ If unanticipated monetary changes can in fact be generated systematically through deceptive policy, it is unclear how such a policy could improve the performance of a wellfunctioning private economy. Clearly, some type of externality or transaction-cost argument would have to be invoked. The more likely outcome of unpredictable monetary policy is that it would exacerbate the information problems faced by private agents, as discussed in Barro (1976, sec. 3). In any case, a convincing normative theory of deceptive (countercyclical) monetary policy has not yet been developed. 
duce another change in basic policy. In any event, if these types of policy changes themselves reflect the workings of the political process or developments in the domestic or international economy, there is no reason to believe that the (average) expectation of changes in policy structure would lag behind the actual changes. Although a period surrounding a discrete change in policy structure might be marked by substantial uncertainty and difference of opinion, it seems just as likely that the average expectation would lead, rather than lag, the actual changes in policy.

\section{Extensions of the Research}

The extension of the anticipated/unanticipated money concept to the determination of the price level fills an important gap in my earlier empirical analysis. Although the results on price level determination seem basically favorable to the approach, there are numerous issues that warrant further attention.

The analysis brings out the role of the nominal interest rate in the determination of the price level. The research could be usefully extended to an explanation of the relation of interest rates to monetary and other variables. I am currently working on a theoretical investigation that relates the anticipated/unanticipated money viewpoint to interest-rate determination. This theoretical work will eventually be implemented empirically.

It would be important to extend the results obtained from recent observations in the United States to the longer time-series experience. This extension is both difficult and potentially fruitful, because it requires an explicit treatment of the types of substantial structural shifts in the money growth process (movements on or off the gold standard, establishment of the Federal Reserve, etc.) that were discussed in Part $\mathrm{V}$ above. The performance of the approach in this environment will be a major test of the usefulness of the anticipated/unanticipated money concept.

Finally, the present analysis does not detail the mechanism by which unanticipated movements in money affect real variables like output and unemployment. The precise channels are likely to involve unanticipated movements in the price level, which are the focus of theoretical models developed by Lucas (1973), Barro (1976), et al. However, the contemporaneous response of the GNP deflator to monetary shocks that has been isolated in the present empirical study may be too weak to provide the principal link between money and output. An extension of the analysis to additional "price" variables like the nominal wage and the wholesale price index and a consideration of producers' inventories may be important in clarifying the process by which monetary shocks translate into output responses. The analysis of interest rates, as discussed above, may also be important in this context. 


\section{References}

$\rightarrow$ Barro, Robert J. "Rational Expectations and the Role of Monetary Policy." $J$. Monetary Econ. 2 (January 1976) : 1-32.

- "Unanticipated Money Growth and Unemployment in the United States." A.E.R. 67 (March 1977): 101-15. (a)

- "Unanticipated Money, Output, and the Price Level in the United States." Univ. Rochester, July 1977. (b)

Darby, Michael R. "The Allocation of Transitory Income among Consumers' Assets." A.E.R. 62 (December 1972): 928-41.

Enzler, J.; Johnson, L.; and Paulus, J. "Some Problems of Money Demand." Brookings Papers Econ. Activity, no. 1 (1976), pp. 261-80.

Federal Reserve Bulletin. (February 1976 and other issues.)

Feige, Edgar L., and Pearce, Douglas K. "Inflation and Incomes Policy: An Application of Time Series Models." J. Monetary Econ. 2 (suppl., The Economics of Price and Wage Controls; 1976): 273-302.

Goldfeld, Stephen M. "The Case of the Missing Money." Brookings Papers Econ. Activity, no. 3 (1976), pp. 683-730.

Gordon, Robert J. "The Impact of Aggregate Demand on Prices." Brookings Papers Econ. Activity, no. 3 (1975), pp. 613-70.

Hamburger, Michael J. "Behavior of the Money Stock: Is There a Puzzle?" J. Monetary Econ. 3 (July 1977): 266-88.

Lucas, Robert E., Jr. "Econometric Testing of the Natural Rate Hypothesis." In The Econometrics of Price Determination Conference, October 30-31, 1972, Washington, D.C., edited by O. Eckstein. Washington: Board of Governors of the Federal Reserve System and Soc. Sci. Res. Council, 1972.

- _ "Some International Evidence on Output-Inflation Tradeoffs." A.E.R. 63 (June 1973) : 326-34.

$\rightarrow \rightarrow$-. An Equilibrium Model of the Business Cycle." J.P.E. 83, no. 6 (December 1975): 1113-44.

Maddala, G. S. Econometrics. New York: McGraw-Hill, 1977.

Oi, Walter: "On Measuring the Impact of Wage-Price Controls: A Critical Appraisal." J. Monetary Econ. 2 (suppl., The Economics of Price and Wage Controls; 1976) : 7-64.

Sargent, Thomas J. "The Persistence of Aggregate Employment and the Neutrality of Money." Unpublished manuscript, 1977.

$\rightarrow$ Sargent, Thomas J., and Wallace, Neil. " 'Rational' Expectations, the Optimal Monetary Instrument, and the Optimal Money Supply Rule." J.P.E. 83, no. 2 (April 1975): 241-54.

Selden, Richard T. "Money and Inflation: Some International Comparisons." Unpublished manuscript, November 1976.

$\rightarrow$ Taylor, John. "Monetary Policy during a Transition to Rational Expectations." J.P.E. 83, no. 5 (October 1975): 1009-21.

U.S. Council of Economic Advisers. Economic Report of the President. Washington: Government Printing Office, 1977.

U.S. Department of Commerce, U.S. Bureau of the Census. Historical Statistics of the United States, Colonial Times to 1970. Washington: Government Printing Office, 1975.

- Statistical Abstract of the U.S. Washington: Government Printing Office, various issues. 